\title{
Corrigendum: An Alternative Perfusion Approach for the Intensification of Virus-Like Particle Production in HEK293 Cultures
}

\author{
Jesús Lavado-García *, Laura Cervera and Francesc Gòdia \\ Grup d'Enginyeria Cellular i Bioprocés, Escola d'Enginyeria, Universitat Autònoma de Barcelona, Barcelona, Spain
}

Keywords: bioreactor, perfusion, ATF, design of experiments, VLP, HFM

\section{A Corrigendum on}

An Alternative Perfusion Approach for the Intensification of Virus-Like Particle Production in HEK293 Cultures

by Lavado-García J, Cervera L and Gòdia F (2020). Front. Bioeng. Biotechnol. 8:617. doi: 10.3389/ fbioe.2020.00617

In the original article, there was a mistake in Figure 2 and its legend as published. The values 51.5 and 100 that appear in the figure and in section $2 \mathrm{~K}$ of the legend should be 515 and 1000 . The correct Figure 2 and its legend appears below.

In the original article, there was also a mistake in Table 1 as published. The values 51.5 and 100

\section{OPEN ACCESS}

Edited and reviewed by:

Peter Neubauer,

Technical University of Berlin,

Germany

*Correspondence: Jesús Lavado-García jesus.lavado@uab.cat

Specialty section: This article was submitted to Bioprocess Engineering, a section of the journal Frontiers in Bioengineering and Biotechnology

Received: 12 May 2021 Accepted: 21 September 2021 Published: 08 October 2021

Citation: Lavado-García J, Cervera $L$ and Gòdia F (2021) Corrigendum: An Alternative Perfusion Approach for the Intensification of Virus-Like Particle

Production in HEK293 Cultures. Front. Bioeng. Biotechnol. 9:708773.

doi: 10.3389/fbioe.2021.708773 that appear in Table 1 for CSPR limits should be 515 and 1000. The corrected Table 1 appears below.

In the original article, there was also an error in the text. The value of $3000 \mathrm{xg}$ in the mentioned centrifugation should be $300 \mathrm{xg}$. A correction has been made to Section 2: Experimental, Sub-section 2.1: "HEK293 mammalian cell line, culture conditions," Paragraph 3:

"For the pseudoperfusion experiments, the total culture volume was $20 \mathrm{ml}$ and media replacement (MR) was carried out centrifuging the culture at $300 \mathrm{xg}$ for 5 min every $12 \mathrm{~h}$ ensuring that the proportional volume of media was replaced depending on the condition. To maintain a MR rate of 2 reactor volume per day (RV/day), $20 \mathrm{ml}$ were replaced every $12 \mathrm{~h}$. For a rate of $1 \mathrm{RV} /$ day, $10 \mathrm{ml}$ were replaced every $12 \mathrm{~h}$ and for a rate of $0.5 \mathrm{RV} /$ day, $5 \mathrm{ml}$ were replaced every $12 \mathrm{~h} . "$

Further, the value of $100 \mathrm{pL} /$ cell/day should be $1000 \mathrm{pL} /$ cell/day in accordance to the previous correction in Table 1 and Figure 2. A correction has been made to Section 3: Results and Discussion, Sub-section 3.2: "Optimization of retransfection by Design of Experiment (DoE) method," Paragraph 1:

"As for the CSPR, the working range was set based on the previous study of the cell growth upon different media replacement rates. The upper limit was set at 1000 and the lower limit at $30 \mathrm{pL} / \mathrm{cell} / \mathrm{day} . "$

Finally, the value of $8.7 \cdot 10^{11} \mathrm{VLP} \cdot \mathrm{L}^{-1} \cdot \mathrm{day}^{-1}$ should be $2.7 \cdot 10^{12} \mathrm{VLP} \cdot \mathrm{L}^{-1} \cdot \mathrm{day}^{-1}$. This value is already correctly presented in Table 2. However, this typo was overlooked in the text when revising the manuscript. The value of $2.7 \cdot 10^{12}$ VLP. $\mathrm{L}^{-1} \cdot$ day $^{-1}$ is the one obtained in this work and $8.7 \cdot 10^{11}$ is the one that it is being compared to.

A correction has been made to Section 3: Results and Discussion, Sub-section 3.4: Intensification of the optimized protocol in bioreactor using ATF, Paragraph 1:

"...the presented work achieved a reactor and media volumetric productivity of $7.1 \cdot 10^{12}$ and $2.7 \cdot 10^{12}$ VLP.L-1.day-1 respectively, improving $26.8 \%$ or 1.36 fold and $67.8 \%$ or 3.1 fold respectively.”

The authors apologize for these errors and state that this does not change the scientific conclusions of the article in any way. The original article has been updated. 
A

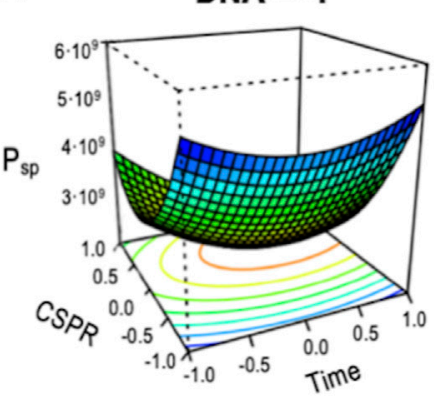

D

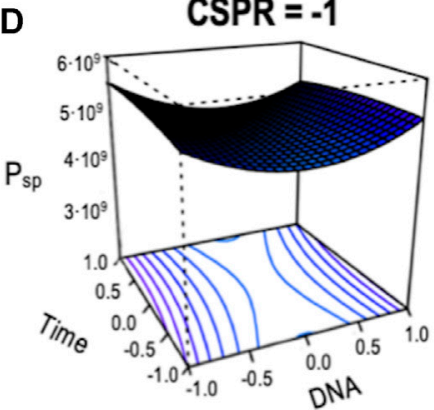

G

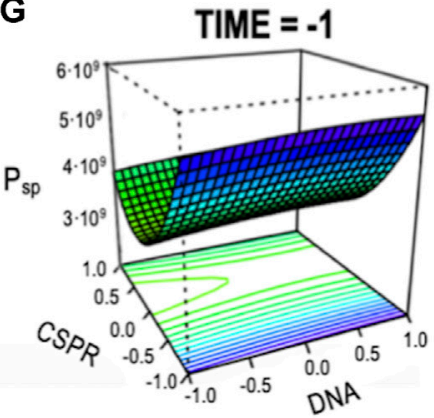

J

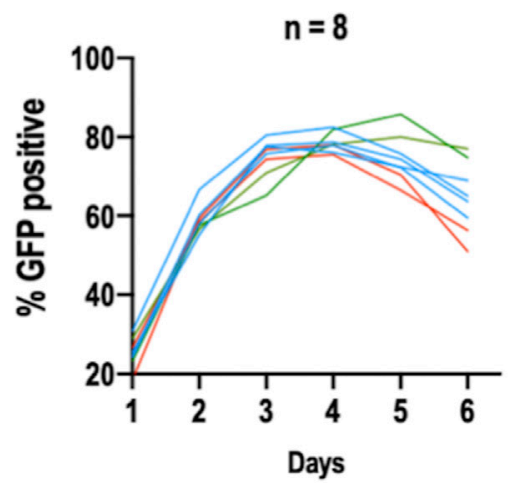

B

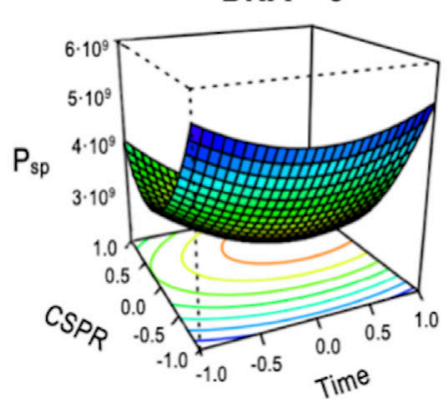

E

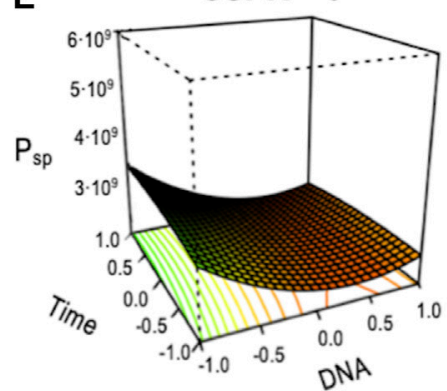

H

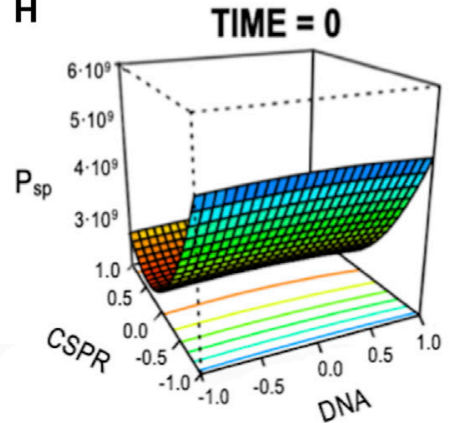

K

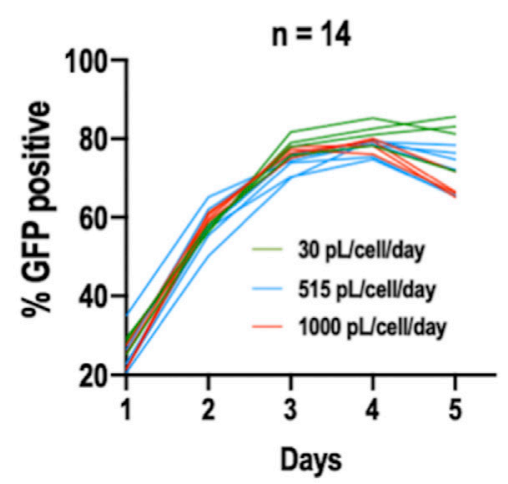

C

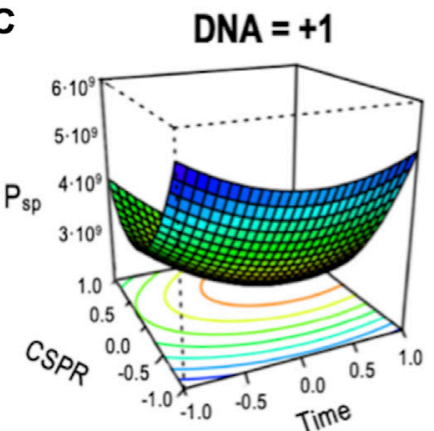

F
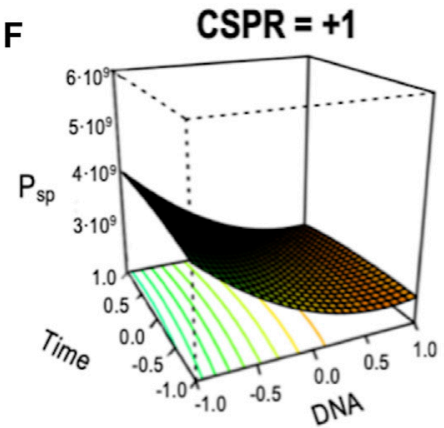

I

TIME = +1

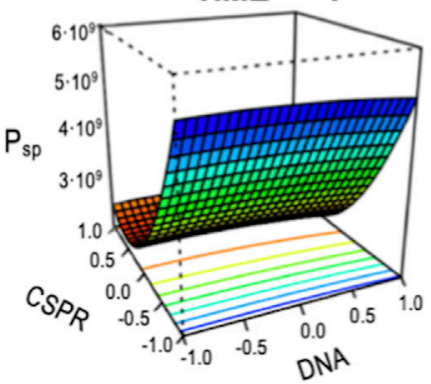

L

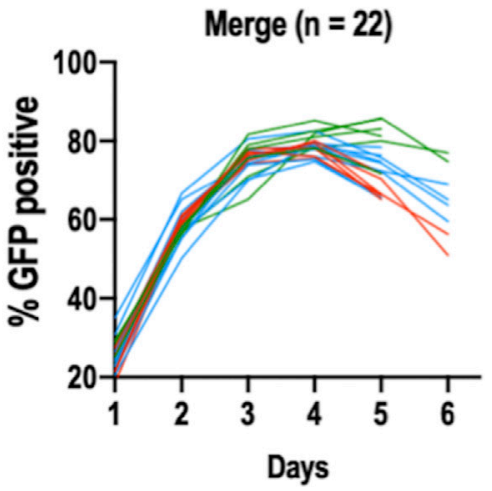

FIGURE 2 |Response surface graphs based on Box-Behnken experimental results. Maximum VLP specific production in cell culture supernatants as a function of (A -C) CSPR vs. Time; (D -F) time vs. DNA; and (G -I) CSPR vs. DNA. The graphs were constructed by depicting two variables at a time and maintaining the third one at a fixed level. +1 , 0, and -1 correspond to $0.5,1.25$, and $2 \mathrm{mg} / \mathrm{ml}$ for the DNA concentration; 30, 515, and $1000 \mathrm{pL} / \mathrm{cell} / \mathrm{day}$ for the CSPR and 24,48 , and 72 hpt for the time of retransfection. $(\mathbf{J}-\mathbf{L})$ represent the changes of the percentage of transfection measured in percentage of GFP positive cells along the studied time course for conditions reaching the sixth day of the process $\mathbf{( J )}$ and conditions reaching the fifth (K). (L) Shows the merged plot. 
TABLE 1 | Box-Behnken design, results and ANOVA analyses for optimization of the extended gene expression (EGE) protocol for VLP production.

\begin{tabular}{|c|c|c|c|c|}
\hline & & -1 & 0 & 1 \\
\hline \multicolumn{2}{|c|}{ Retransfection time (hpt) } & 24 & 48 & 72 \\
\hline \multicolumn{2}{|c|}{ CSPR (pL/cell/day) } & 30 & 515 & 1000 \\
\hline \multicolumn{2}{|c|}{ DNA $(\mathrm{mg} / \mathrm{mL})^{\mathrm{a}}$} & 0.5 & 1.25 & 2 \\
\hline Experimental run & Retransfection time & CSPR & DNA/mL & $\mathbf{P}$ \\
\hline 1 & 1 & 0 & -1 & $1.83 E+09$ \\
\hline 2 & 1 & 0 & -1 & $2.20 \mathrm{E}+09$ \\
\hline 3 & -1 & 0 & -1 & $2.68 \mathrm{E}+09$ \\
\hline 4 & -1 & 0 & -1 & $3.29 E+09$ \\
\hline 5 & 1 & 0 & 1 & $1.85 E+09$ \\
\hline 6 & 1 & 0 & 1 & $1.92 E+09$ \\
\hline 7 & 0 & -1 & -1 & $5.06 \mathrm{E}+09$ \\
\hline 8 & 0 & -1 & -1 & $4.33 E+09$ \\
\hline 9 & 0 & 1 & -1 & $2.32 E+09$ \\
\hline 10 & 0 & 1 & -1 & $2.36 E+09$ \\
\hline 11 & 0 & 1 & 1 & $2.10 E+09$ \\
\hline 12 & 0 & 1 & 1 & $2.47 E+09$ \\
\hline 13 & -1 & 1 & 0 & $4.64 E+09$ \\
\hline 14 & -1 & 1 & 0 & $2.91 E+09$ \\
\hline 15 & 1 & -1 & 0 & $5.21 E+09$ \\
\hline 16 & 1 & -1 & 0 & $5.56 \mathrm{E}+09$ \\
\hline 17 & 0 & 0 & 0 & $2.07 E+09$ \\
\hline 18 & 0 & 0 & 0 & $1.92 E+09$ \\
\hline 19 & 0 & 0 & 0 & $1.72 E+09$ \\
\hline 20 & 0 & 0 & 0 & $1.89 E+09$ \\
\hline 21 & 0 & -1 & 1 & $5.19 E+09$ \\
\hline 22 & 0 & -1 & 1 & $4.10 E+09$ \\
\hline 23 & 1 & 1 & 0 & $2.25 E+09$ \\
\hline 24 & 1 & 1 & 0 & $1.94 E+09$ \\
\hline 25 & -1 & 0 & 1 & $2.40 E+09$ \\
\hline 26 & -1 & 0 & 1 & $4.07 E+09$ \\
\hline 27 & -1 & -1 & 0 & $5.65 E+09$ \\
\hline 28 & -1 & -1 & 0 & $5.19 \mathrm{E}+09$ \\
\hline 29 & 0 & 0 & 0 & $2.12 E+09$ \\
\hline 30 & 0 & 0 & 0 & $2.38 E+09$ \\
\hline Model & Multiple $\mathbf{R}^{2}$ & $P$ value $^{b}$ & Lack of $\mathrm{fit}^{\mathrm{c}}$ & - \\
\hline- & 0.9126 & 1.06E-08 & 0.9316 & - \\
\hline Parameters & Coefficient & - & $t$ & $P$ Value $^{\mathrm{b}}$ \\
\hline Constant & $0.02 E+09$ & - & 10.225 & $<0.0001$ \\
\hline (Time) & $-5.04 E+08$ & - & -4.1761 & 0.0005 \\
\hline (CSPR) & $-1.21+09$ & - & -9.9874 & $<0.0001$ \\
\hline (DNA) & $1,88 E+06$ & - & 0.0155 & 0.988 \\
\hline (Time)-(CSPR) & $-4.11 E+08$ & - & -2.4077 & 0.026 \\
\hline (Time)-(DNA) & $-9.50 E+07$ & - & -0.5562 & 0.584 \\
\hline (CSPR)-(DNA) & $-1.25 E+06$ & - & --0.0073 & 0.994 \\
\hline$(\text { Time })^{2}$ & $5.95 E+08$ & - & 3.3492 & 0.003 \\
\hline$(\mathrm{CSPR})^{2}$ & $1.56 E+09$ & - & 8.7562 & $<0.0001$ \\
\hline$(\mathrm{DNA})^{2}$ & $-8.21 E+07$ & - & -0.4617 & 0.649 \\
\hline Optimal Values & - & - & - & - \\
\hline- & Time of Retransfection & CSPR & DNA & $P_{s p}$ \\
\hline- & -1 & -1 & 0.5977154 & $5.49 E+09$ \\
\hline- & At $24 \mathrm{hpt}$ & $30 \mathrm{pL} / \mathrm{cell} / \mathrm{day}$ & $1.7 \mu \mathrm{g} / \mathrm{ml}$ & - \\
\hline
\end{tabular}

${ }^{a}$ DNAVPEI ratio was always maintained at (1:2)

${ }^{b} \mathrm{p}$ values under 0.05 are considered statistically significant with $95 \%$ confidence, and under 0.1 , statistically significant with $90 \%$. ${ }^{c} \mathrm{p}$ values associated to lack of fit test above 0.05 mean that the hypothesis arguing that the model is suitable cannot be rejected. hpt: hours post transfection

Publisher's Note: All claims expressed in this article are solely those of the authors and do not necessarily represent those of their affiliated organizations, or those of the publisher, the editors and the reviewers. Any product that may be evaluated in this article, or claim that may be made by its manufacturer, is not guaranteed or endorsed by the publisher.
Copyright $\odot 2021$ Lavado-García, Cervera and Gòdia. This is an open-access article distributed under the terms of the Creative Commons Attribution License (CC BY). The use, distribution or reproduction in other forums is permitted, provided the original author(s) and the copyright owner(s) are credited and that the original publication in this journal is cited, in accordance with accepted academic practice. No use, distribution or reproduction is permitted which does not comply with these terms. 